\title{
Adaptation of a patient activatıon measure (PAM) into Turkish: reliability and validity test
}

\author{
Cansu Kosar ${ }^{1}$, Dilek Buyukkaya Besen ${ }^{2}$
}

1. Internal Medicine Nursing Department, Dokuz Eylul University Health Sciences Institute

2. Internal Medicine Nursing Department, Dokuz Eylul University Izmir / TURKEY

\section{Emails:}

Cansu Kosar: cansukosar@hotmail.com; Dilek Buyukkaya Besen: buyukkayabesen@gmail.com

\begin{abstract}
:
Background: Patient activation is a central concept in chronic illness care model. Activated patients have ability and willingness to manage their health.

Objective: Aim of this study was to test the reliability and validity of a Patient Activation Measure.

Methods: Research sample consisted of 130 patients who had diabetes, hypertension or rheumatoid arthritis. Data was collected through socio-demographic information form and a Patient Activation Measure (PAM). Reliability and validity of PAM were analyzed.

Results: Internal consistency reliability coefficient of the PAM was $\alpha: .81$. Correlation coefficients between item and total scale scores varied from .38 to .66. Result of explanatory factor analysis Kaiser Meyer Olkin coefficient was .75 and Barlett test was x2: 646.870; p: 0. 000. Result of confirmatory factor analysis, model fit indexes were x2/df: 1.59, RMSEA: 0.071, CFI: 0.96, NNFI: 0.95. The result of Rasch analysis, reliability coefficient varied from 0.83 to 0.87 and in validity assesment, item fit statistics for INFIT varied from 0.68 to 1.53 and for OUTFIT varied from 0.65 to 1.54 .

Conclusion: PAM has enough validy and reliability for use in determining activation scores and level of the patients in Turkey. It could be used in planing appropriate interventions for the activation level and help to improve self management.

Keywords: Patient activation measure (pam), reliability, validity, test.

DOI: https://dx.doi.org/10.4314/ahs.v19i1.58

Cite as: Kosar C, Besen DB. Adaptation of a patient activation measure (PAM) into Turkish: reliability and validity test. Afri Health Sci. 2019;19(1). 1811-1820. bttps:// dx.doi. org/10.4314/ abs. v19i1.58
\end{abstract}

\section{Introduction}

Patient activation is a key element which refers to patients' willingness and capacity in managing their own health, undertaking their care and in gaining the basic knowledge about their conditions ${ }^{1,2}$. Patients who are more highly activated believe that they had an important role in self-management of their own care, interact with supportive people, know how to manage their condition,

\section{Corresponding author: \\ Cansu Kosar, \\ Dokuz Eylul University, \\ Dokuz Eylul University Health \\ Campus Inciralt1 / 35340 IZMIR/ TURKEY. \\ Phone number: 0536746060 \\ Email: cansukosar@hotmail.com}

protect and maintain their health functions, prevent regression in their health and access appropriate high-quality care ${ }^{3,4}$. Hibbard et $\mathrm{al}^{3,4}$ defined patient activation as a concept and elements of the concepts were found to be knowledge, skills, beliefs and self-confidence for managing health.

Patient activation is divided into these four developmental levels; Belief that taking an active role is important, knowledge and confidence for taking action, taking action and maintaining routines even while under stress ${ }^{2,3,4}$. In the first level, patients tend to be passive and feel overwhelmed by managing their own health. They may not understand their role in the care process ${ }^{2,3}$. In the second level, patients may lack the knowledge and confidence to manage their health ${ }^{2,3}$. In the third level, patients appear to be taking action but may still lack the confidence and 
skill to support their behaviours ${ }^{2,3}$. In the fourth level, patients adopt many of the behaviours needed to support their health but may not be able to maintain them in the face of life stressors ${ }^{2,3}$.

Dixon et $\mathrm{l}^{5}$ evaluated that patients' self-management approach who were at different levels of activation. They stated that the patients who had low levels of activation tended to see successful self-management as compliance whereas those at higher activation levels saw it as being in control. In addition, patients who had lower activation levels were prone to see lack of knowledge and lack of confidence as barriers ${ }^{5}$. Patient activation is related to engagement in preventive behaviours, treatment and healthy behaviours ${ }^{6,7}$. Empirical studies indicate that people who are more activated are significantly more likely to engage in healthy behaviours like eating a healthy $\operatorname{diet}^{3,4,6}$ or taking regular exercise $e^{2,8,9,10,11,12,13}$ compared with people who score lower on the activation scale. Conversely, less activated patients are significantly less likely to have prepared questions for a visit to the doctor, to know about treatment guidelines for their condition or to be persistent in asking if they don't understand what their doctor has told them $^{8,14}$. Wong, Petersonve Black found that there was a positive correlation between patient activation scores and patient provider interactions. Positive interactions between the patient and the provider influenced the patient's abilities to engage in and be confident in maintaining health ${ }^{15}$. Becker and Roblin stated that supportive interactions between patients and physicians contributing to patients who take a more active role in their health ${ }^{16}$.

Research shows that patient activation can robustly predict some health behaviours. It is directly associated with clinical outcomes. Highly activated patients are more likely to adopt healthy behaviour, to have better clinical outcomes and lower rates of hospitalisation, and to report higher levels of satisfaction with services $2,6,7,9,13$. Patient Activation Measure (PAM) has been developed and translated in many countries to measure patients activation in terms of beliefs, knowledge, skill and self-confidence ${ }^{17,18,19,20,21,22}$. The purpose of this study was to test the validity and reliability of the Patient Activation Measure translated to Turkish in a Turkish population.

\section{Methods}

\section{Research design}

This was a methodological study, because the aim was to test the reliability and validity of PAM, the research steps and statistical analysis methods, which are used in methodological studies (content validity index, exploratory and confirmatory factor analysis...) were used in this research.

\section{Sample}

In reliability analysis the standard advice is to have at least 10 participants per item on the scale ${ }^{31}$. Since the scale tested in this study was composed of 13 items, the sample of this study included 130 patients with chronic diseases. Among the patients who were referred to internal medicine policlinics in the university hospital, 130 patients were selected according to the following criteria; have any one of these diabetes, hypertension, rheumatoid arthritis, non-malignancy, diagnosis: aged 18 years and above, able to speak and read Turkish, willingness to be a participant. Data was collected by using a sociodemographic questionnaire and a Patient Activation Measure. The study was conducted between December 2014 and February 2015 in a university hospital in Izmir, Turkey.

\section{Instruments}

\section{A Socio-demographic questionnare}

A socio-demographic questionnaire was developed by the authors to capture personal information on age, gender, education, marital status, having children, employment status, income, perceived health and chronic diseases.

\section{Patient activation measure}

Patient Activation Measure (PAM) was developed by Hibbard et al. in patients with chronic diseases in 2004 to determine patient activity and its short version was tested in another patient group with chronic diseases in 2005. PAM is a valid and highly reliable on the Guttmann scale which has one factor structure and 13 items. Higher scores for the scale show higher patient activation: Participation in disease management actively/successful self-management.

The answering categories per item are 4-point Likert scales, ranging from totally disagree to totally agree and 'non applicable'. Activity scores vary from 0 to 100 . Level 1 , the lowest activity with scores of $<47$, refers to believing in the importance of taking an active role. Level 2 with scores of 47-55 refers to having knowledge and confidence to take action. Level 3 with scores of 55-72 refers to taking action. Level 4 , the highest activity with scores of $>72.5$, refers to maintaining routines even under stress ${ }^{5,6}$. 


\section{Data collection}

The study purpose, procedural details, the participants rights, potential benefits andrisks of the study were explained to patients and informed written consent was taken from them. Data was collected by using a socio-demographic questionnare, and a Patient Activation Measure by the first researcher. Each data collection session took a range of 15 to 20 minutes.

\section{Data analysis}

Data were analyzed in computer environment with SPSS, Winsteps and LISREL programme. SPSS was used forreliability tests and exploratory factor analysis, LISREL was used for confirmatory factor analysis and Winsteps was used for Rasch analysis.

\section{Translation and adaptation}

Linguistic validity of PAM was achieved by translation-backtranslation method. The scale was translated from English to Turkish by two experts whose native languages were Turkish. After the most appropriate expressions were selected and one single Turkish version was created, it was back translated to English by two other experts who had good command of both languages and did not have any relation with first two experts. Blinding was taken as basis in this stage. The back translated version of the scale was compared with the original one and the Turkish version was evaluated by a linguist. Right after, twelve experts evaluated content validity of all items and content validity rate was calculated. In this way the last version of the scale was created ${ }^{23}$. Ultimately the scale was piloted on ten patients.

\section{Validity}

Construct validity of the scale was evaluated with exploratory factor analysis (EFA) and confirmatory factor analysis (CFA). Kaiser-Meyer Olkin (KMO) coefficient was used to determine whether the sample size was sufficient and Barlett's test was used to determine whether data were appropriate for factor analyses. In EFA, principal component analysis was made to determine whether the scale had a one-factor structure and also explained variance and factor loads of each item were calculated. In CFA, model fit indices and factor loads of the items were examined. Item difficulty and item one-factor structure of the scale was evaluated with fit statistics with Rasch analysis.

\section{Reliability}

Reliability was tested using internal consistency analyses and coefficient of invariance. Internal consistency was analyzed with Cronbach's $\alpha$ reliability coefficient, item-total score analysis and item analysis based on lower-upper group means. Reliability over time was evaluated with the test-retest method. Reliability coefficient was calculated with Rasch analysis.

\section{Ethical considerations}

Permission was requested from the authors who developed PAM via e-mail. This study was cleared by the Research Ethics Committee of the 9 Eylul University Faculty of Medicine at Izmir, Turkey. Approval was obtained from Dokuz Eylul University Hospital Administration and the departments of Endocrine, Rheumatology and Cardiology. Written informed consent was taken from the patients volunteering to participate in the study after they were explained the purpose of the study.

\section{Results \\ Socio-demographic features}

Among 130 patients, $71.5 \%$ were female and $28.5 \%$ were male. The mean age of the patients was $56.7 \pm 13.8$ years. $16.9 \%$ of all patients were university graduates, $19.2 \%$ were high school graduates, $13.8 \%$ were secondary school graduates, $44.6 \%$ were primary school graduates and $5.4 \%$ were just literate. $13.8 \%$ of the patients had a job, but $86.2 \%$ of the patients did not have a job (unemployed or retired). $84.6 \%$ of the patients were married and $15.4 \%$ were single. Of all the patients, $60.8 \%$ had income equal to expenses, $28.5 \%$ had income lower than expenses and $10.8 \%$ had income higher than expenses. $87.7 \%$ of the patients had a child. Perceived health status was very good in $2.3 \%$ of the patients, good in $22.3 \%$, fair in $59.2 \%$ and poor in $16.2 \%$ of the patients (Table 1 ). 
Table 1. Demographic data of the PAM for Turkish sample $(n=130)$

\begin{tabular}{|c|c|c|}
\hline Sociodemographic Characteristics & & SD \\
\hline \multirow[t]{2}{*}{ Age } & 56.71 & \pm 13.82 \\
\hline & n & $\%$ \\
\hline \multicolumn{3}{|l|}{ Gender } \\
\hline Female & 93 & 71.5 \\
\hline Male & 37 & 28.5 \\
\hline \multicolumn{3}{|l|}{ Educational status } \\
\hline Literate & 7 & 5.5 \\
\hline Primary School & 58 & 44.6 \\
\hline Secondary School & 18 & 13.8 \\
\hline High School & 25 & 19.2 \\
\hline University & 22 & 16.9 \\
\hline \multicolumn{3}{|l|}{ Marital Status } \\
\hline Married & 110 & 84.6 \\
\hline Single & 20 & 15.4 \\
\hline \multicolumn{3}{|l|}{ Having child } \\
\hline Yes & 114 & 87.7 \\
\hline No & 16 & 12.3 \\
\hline \multicolumn{3}{|l|}{ Having a job } \\
\hline Yes & 18 & 13.8 \\
\hline No & 112 & 86.2 \\
\hline \multicolumn{3}{|l|}{ Income Status } \\
\hline Income lower than expenses Income & 37 & 28.4 \\
\hline equal to expenses & 79 & 60.8 \\
\hline Income higher than expenses & 14 & 10.8 \\
\hline \multicolumn{3}{|l|}{ Self - rated Health } \\
\hline Poor & 21 & 16.2 \\
\hline Fair & 77 & 59.2 \\
\hline Good & 29 & 22.3 \\
\hline Very good & 3 & 2.3 \\
\hline
\end{tabular}

\section{PAM scores}

PAM scores of the participants ranged from $28.8 \%$ to $83.3 \%$. Up to $28.7 \%$ of patients were in activation level 1 , $44.9 \%$ were in activation level $2,20.2 \%$ were in activation level 3 and $6.20 \%$ were in activation level 4 .

\section{Translation and cultural adaptation}

After linguistic validity of PAM was achieved, expert opinion was requested for contentvalidity index. Content validity index was found to be higher than 0.56 for each item and 0.98 for the scale.

PAM was piloted on 10 patients. Since the expression "medical treatment" in item 7 was not understood easily, the item was changed into "I am not sure whether medical treatment (nutrition, exercise, drug treatment) can be maintained at home". Upon receiving positive feedbacks following this change, the scale was used for data collection in the study sample.

\section{Psychometric features of PAM Validity}

Construct validity of PAM was examined with exploratory and confirmatory factor analyses (CFA). KMO coefficient was 0.75 . Barlett's test showed a significant result (x2: 646.870; p: 0.000). 
In CFA, principal component analysis (PCA) was made to determine whether PAM hada one factor structure. Eigen value of the resultant factor was 4.3, which is higher than the significant value 1 . Total variance explained by this factor was $33.1 \%$. Factor loadings of the items ranged from 0.42 to 0.71 . The factor loads of PAM were over 0.30 .

In EFA, one factor was tested since the original version of PAM had a one-factor structure. Model fit indices of the scale were as in the following: x2: 98.7, df: 62, x2/ df: 1.59, RMSEA: 0.071, GFI: 0.88, CFI: 0.96, NFI: 0.90. According to EFA factors loadings of the items ranged between 0.39 and 0.71 . All the factor loads were found to be over 0.30 .

\section{Reliability}

Cronbach's alpha internal consistency coefficient was 0.81. Item-total correlation coefficients ranged from 0.38 to 0.66. PAM was found to have item-total correlation coefficients of over 0.30 (Table 2).

Table 2. Item-Item Total Score Correlation of PAM $(n=130)$

\begin{tabular}{lcc}
\hline Items & \multicolumn{2}{c}{$\begin{array}{c}\text { Item- Item Total Score } \\
\text { Correlation }\end{array}$} \\
\cline { 2 - 3 } & $\mathrm{r}$ & $\mathrm{p}$ \\
\hline $\mathbf{1}$ & .58 & .000 \\
\hline $\mathbf{2}$ & .59 & .000 \\
\hline $\mathbf{3}$ & .39 & .000 \\
\hline $\mathbf{4}$ & .60 & .000 \\
$\mathbf{5}$ & .54 & .000 \\
\hline $\mathbf{6}$ & .46 & .000 \\
\hline $\mathbf{7}$ & .65 & .000 \\
\hline $\mathbf{8}$ & .63 & .000 \\
\hline $\mathbf{9}$ & .66 & .000 \\
\hline $\mathbf{1 0}$ & .38 & .000 \\
\hline $\mathbf{1 1}$ & .47 & .000 \\
\hline $\mathbf{1 2}$ & .39 & .000 \\
\hline $\mathbf{1 3}$ & .53 & .000 \\
\hline
\end{tabular}

Independent groups t-test showed a significant difference between upper and lower group means for each item in the scale $(\mathrm{p}<0.05)$.

To determine test-retest reliability, scale was administered to the same patient group two times at a two-weeks interval and correlations were examined. The correlation coefficient was 0.98 for PAM and ranged from 0.59 to 0.93 for the items (Table 3). 
Table 3. Test-retest reliability of PAM $(n=30)$

\begin{tabular}{lcc}
\hline Items & \multicolumn{2}{c}{ Test-retest Correlation } \\
\cline { 2 - 3 } & $\mathrm{r}$ & $\mathrm{p}$ \\
\hline $\mathbf{1}$ & 0.75 & 0.000 \\
\hline $\mathbf{2}$ & 0.72 & 0.000 \\
\hline $\mathbf{3}$ & 0.88 & 0.000 \\
\hline $\mathbf{4}$ & 0.91 & 0.000 \\
\hline $\mathbf{5}$ & 0.62 & 0.000 \\
\hline $\mathbf{6}$ & 0.91 & 0.000 \\
\hline $\mathbf{7}$ & 0.91 & 0.000 \\
\hline $\mathbf{8}$ & 0.96 & 0.000 \\
\hline $\mathbf{9}$ & 0.93 & 0.000 \\
\hline $\mathbf{1 0}$ & 0.93 & 0.000 \\
\hline $\mathbf{1 1}$ & 0.91 & 0.000 \\
\hline $\mathbf{1 2}$ & 0.59 & 0.000 \\
\hline $\mathbf{1 3}$ & 0.89 & 0.000 \\
\hline Total score & 0.98 & 0.000 \\
\hline
\end{tabular}

\section{Rasch analysis for validity}

\section{Examination of Item difficulty}

In Rasch analysis, the unit of measurement is called logit, ranging from 0 to 100 . Item difficulty can vary between 38.9 and 61.4. In the present study, based on the item difficulty level analysis results, the items of 4 and 6 were the easiest ones and the items of 9 and 13 were the most difficult ones (Table 4).

\section{Evaluation of Item fit statistics}

Unweighted mean squares (OUTFIT) and weighted mean squares (INFIT) are evaluated to test whether the scale has a one-factor structure. When mean squares are 0.6-1.4, the sample size given is considered sufficient for a good model fit. INFIT values for items of PAM ranged between 0.68 and 1.53 and OUTFIT values ranged from 0.65 to 1.54 . It is showed that all 13 items had a good model fit. Only item 13 had slightly high OUTFIT and INFIT values, which can be considered as acceptable (Table 5). 
Table 4. Item difficulty Structure of PAM

\begin{tabular}{lc}
\hline Items & Item difficulty Structure Values \\
\hline $\mathbf{1}$ & 40.9 \\
\hline $\mathbf{2}$ & 41.3 \\
\hline $\mathbf{3}$ & 49.6 \\
\hline $\mathbf{4}$ & 40.6 \\
\hline $\mathbf{5}$ & 49.0 \\
\hline $\mathbf{6}$ & 38.9 \\
\hline $\mathbf{7}$ & 46.4 \\
\hline $\mathbf{8}$ & 53.2 \\
\hline $\mathbf{9}$ & 61.4 \\
\hline $\mathbf{1 0}$ & 54.0 \\
\hline $\mathbf{1 1}$ & 47.2 \\
\hline $\mathbf{1 2}$ & 50.8 \\
\hline $\mathbf{1 3}$ & 61.1
\end{tabular}

Table 5. Item Fit Statistics of PAM $(n=130)$

\begin{tabular}{llc}
\hline Items & Infit & Outfit \\
\hline $\mathbf{1}$ & 0.80 & 0.83 \\
\hline $\mathbf{2}$ & 0.68 & 0.71 \\
\hline $\mathbf{3}$ & 0.75 & 0.77 \\
\hline $\mathbf{4}$ & 1.05 & 0.99 \\
\hline $\mathbf{5}$ & 0.78 & 0.79 \\
\hline $\mathbf{6}$ & 1.44 & 1.46 \\
\hline $\mathbf{7}$ & 0.91 & 0.89 \\
\hline $\mathbf{8}$ & 0.97 & 0.96 \\
\hline $\mathbf{9}$ & 0.94 & 0.94 \\
\hline $\mathbf{1 0}$ & 1.30 & 1.40 \\
\hline $\mathbf{1 1}$ & 0.68 & 0.65 \\
\hline $\mathbf{1 2}$ & 1.09 & 1.09 \\
\hline $\mathbf{1 3}$ & 1.53 & 1.54 \\
\hline
\end{tabular}




\section{Rasch analysis for reliability}

Reliability of the scale is evaluated with person reliability. Separation reliability coefficientand separation index are calculated. Upper/model reliability coefficient and lower /real reliability coefficient for Turkish version of PAM were 0.87 and 0.83 respectively and the person reliability coefficient ranged from 0.87 to 0.83 . Since the desirable reliability coefficient is 0.8 and over, the measurement was observed to assign people and items into four levels.

\section{Discussion \\ Validity}

Factor structure of PAM was evaluated with PCA and the total variance explained by theresultant factor was 33.1\% (Eigen value 4.3) in the present study. When variance explained by one factor structure is $30 \%$ or higher, it can be considered sufficient ${ }^{14,24}$. As in theoriginal scale, the Turkish version had a single factor. The total variance explained by the primary factor was $40.9 \%$ and the Eigen value was 5.3 in German version ${ }^{17}$. The total variance was $34.5 \%$ and the Eigen value was 4.5 in German version ${ }^{18}$. The total variance was $43.2 \%$ in Danish version ${ }^{19}$ and $57.5 \%$ in Korean version of the scale ${ }^{20}$.

Factor loads of the scale ranged from 0.42 to 0.71 in the present study. It has been reported in the literature that factor loads of $0.30-0.40$ could be considered as lower cut-off points in creation of the factor structure ${ }^{24,25}$. EFA revealed that all 13 items of PAM loadedon one factor. CFA revealed the following model fit indices in the current study: x2/df: 1.59; RMSEA: 0.071, GFI: 0.88, CFI: 0.96, NFI: 0.90 and NNFI: $0.95 . \chi^{2 / \mathrm{df}<3}$ shows a good model fit and RMSEA 0.05 - 0.08 is acceptable, GFI > 0.85 - model is enough to data fit, CFI $>0.90, \mathrm{NFI}>0.90$ and NNFI $>0.90$ required values, The results are indicate that the model has a good $\mathrm{fit}^{26,27,28,29,30}$. CFA showed that factor loads of PAM ranged from 0.39 to $0.71(>0.30)$. Fit indices obtained through CFA provides support for construct validity of PAM.

\section{Reliability}

Cronbach alpha internal consistency coefficient for the scale was 0.81 . That shows the scalewas highly reliable $24,25,31,32$. Cronbach's alpha was 0.91 for the original scale developed by Hibbard et al. ${ }^{3}, 0.88$ for the German version $^{17}, 0.89$ for the Danish version ${ }^{19}, 0.88$ for the Korean version ${ }^{20}, 0.77$ for the Hebrew version ${ }^{21}$ and 0.88 for the Dutch version ${ }^{22}$. It is clear that Cronbach's alpha obtained in the present study is close to the one reported in the literature.

According to item analysis, item-total correlation coefficients for PAM ranged from 0.38 to 0.66. In general, the items with an item-total correlation coefficient of minimum 0.30 distinguish individuals well ${ }^{24,25,32}$. Since all items had a correlation coefficient higher than 0.30 , they measure similar characteristics. The item-total correlation coefficient was reported to be $0.46-0.63$ for the German version $^{17}, 0.48-0.65$ for the Danish version ${ }^{19}, 0.32-0.71$ for the Korean version ${ }^{20}$ and $0.46-0.66$ for the Dutch version $^{22}$. The item-total correlation coefficient found in the present study is similar to those reported in the literature.

Test-retest was performed to evaluate reliability of PAM across time. The correlation coefficient between the two administrations was 0.98 for the scale and ranged from 0.59 to 0.93 between the items. It was reported to be 0.47 and range from 0.25 to 0.49 for each item for the Dutch version22. It can be stated that PAM is reliable across time.

Item analysis based on differences between upper and lower group means was performed to determine how sufficient PAM is to distinguish patients regarding activation. There was a significant difference between upper and lower group means for each item in thescale $(\mathrm{p}<0.05)$. All the items could differentiate the first 35 and the last 35 participants who got the highest and the lowest scores respectively. It is clear that the scale can discriminate activation between individuals getting the highest and the lowest scores.

\section{Evaluation of validity with rasch analysis} Examination of Item Difficulty with Rasch Analysis In the present study, analysis of item difficulty in PAM showed that the easiest items were 4 and 6 and the most difficult items were 9 and 13 for the Turkish population. The item difficulty order arising in the present study was consistent with the one found in the original scale in general. As in the original scale, items 1, 2 and 4 are easiest ones and items 9,10 and 13 are more difficult ones for the Turkish population. However, there are some differences in item difficulty order between the Turkish version of PAM and the original scale. It may be that $74 \%$ of the sample of this study had activity levels 1 and 2, that is, in- 
dividuals without sufficient confidence and knowledge of their health problems. Also cultural differences between Turkish and American populations may be the reason; that is, protective relatives put the person into patient role easily and they may not give enough responsibility to patient for health care activities.

\section{Evaluation of Item fit statistics with rasch analysis}

Item fit statistics analyzed to determine whether the Turkish version of PAM had one factor structure, showed that INFIT values of the items ranged from 0.68 to 1.53 and that OUTFIT values of the items ranged from 0.65 to 1.54 . Since these values were between 0.6 and 1.4 , all 13 items had a good model fit. The values for item 13 seemed to be slightly high, but they were acceptable ${ }^{3,4}$. INFIT and OUTFIT values of the short version of PAM were 0.92-1.05 and 0.85-1.11 respectively ${ }^{3}$. In the Danish version, INFIT values were $0.67-1.34$ and the OUTFIT values were $0.69-1.1617$. In the Hebrew version, INFIT and OUTFIT values were $0.70-1.35$ and $0.73-1.45^{19}$. In the Korean version, INFIT values were $0.68-1.42$ and OUTFIT values were $0.68-1.54^{20}$. In the German version, INFIT and OUTFIT values were $0.68-1.03$ and 0.65 $-1.22^{21}$. It is clear that INFIT and OUTFIT values for the Turkish version were close to those for the other versions. The finding that these values were in the expected range confirms its one factor structure.

\section{Evaluation of reliability with rasch analysis}

Upper / model reliability coefficient was 0.87 and lower / real reliability coefficient was 0.83 for the Turkish version of PAM and the person reliability coefficient ranged between these values. Since the desirable person reliability coefficient was 0.8 and higher than 0.8 , the Turkish version had a good discriminatory index, could divide a sample into four activity levels and had sufficient reliability ${ }^{3,4}$. The person reliability coefficient was reported to be 0.87 0.91 for the original scale 1 and $0.81-0.85$ for the short version by Hibbard et al. ${ }^{3}$ It was found to be $0.83-0.85$ for the Danish version and 0.87-0.89 for the Korean ver$\operatorname{sion}^{19,20}$. It is obvious that the Turkish version of PAM is similar to other versions reported in the literaturein terms of person reliability.

\section{Conclusion}

The results showed that Turkish translation of PAM is a valid and reliable tool to assess patient activation in pa- tients with chronic diseases. Only the order of the items wasn't the same one to one with the original version of PAM.

\section{Implications for practice}

Health professionals encourage patients to get involved in care, but they do not usually know about abilities and skills of patients individually. Therefore, they design and implement the same interventions. Knowing patient activation score and level will allow planning appropriate interventions by activity levels of the patients. This method could increase patient activation gradually, thereby patients can build confidence and skills necessary for effective self management and health outcomes can improve. It provides guidance for self-management education programs, allows health professionals to design patient specific interventions and helps to improve health outcomes.

\section{Conflict of interest}

All authors have no conflict of interest.

\section{References}

1. Greenfield S, Kaplan S, Ware JE. Expanding patient involvement in care effects on patient outcomes. Annals ol Internal Medicine. 1985; 102: 520-528.

2. Hibbard JH, Mahoney ER, Stock R, Tusler M. Do Increases in patient activation result in improved self -management behaviors. Health Research and Educational Trust. 2007; 42: 1443 -1463.

3. Hibbard JH, Mahoney ER, Stock R, Tusler M. Development of the Patient Activation Measure (PAM): Conceptualizing and measuring activation in patients and consumers. HSR: Health Services Research. 2004; 39: 10051026.

4. Hibbard JH, Mahoney ER, Stock R, Tusler M. Development and testing of a short form of the patient activation measure. HSR: Health Services Research. 2005; 40:19181930.

5. Dixon A, Hibbard J, Tusler M. How do people with different levels of activation self manage their chronic conditions. Patient. 2009; 2: 257-268.

6. Greene J, Hibbard J. Why Does patient activation matter? an examination of the relationships between patient activation and health-related outcomes. J Gen Intern Med. 2012; 27: 520-6.

7. Hibbard JH, Greene J. What the evidence shows about patient activation: Better health outcomes and care ex- 
periences; fewer data on costs. Health Affairs. 2013; 32: 207-214.

8. Fowles JB, Terry P, Xi M, Hibbard J,Bloom CT, Harvey L. Measuring selfmanagement of patients and employees health: further validation of the PatientActivation Measure (PAM) based on its relation to employee characteristics. Patient Education and Counseling. 2009; 77: 116-22. 9. Rask K, Ziemer D, Kohler S, awley J.N, Arinde F, Barnes CS. Patient activation isassociated with healty behaviors and ease in managing diabetes in an Indigent population. The Diabetes Educator. 2009;35: 622-630.

10. Becker ER, Roblin DW. Translating primary care practice climate into patient activation: the role of patient trust in physician. Medical Care. 2008; 46: 795-805.

11. Hibbard JH, Cunningham PJ. How engaged are consumers in their health and health care, and why does it matter?. Health System Change Research Briefs. 2008; 8: 1-9.

12. Hibbard JH, Tusler. Assessing activation stage and employing a "next steps" approach to supporting patient self-management. Journal of Ambulatory Care Management. 2007; 30: 2-8.

13. Mosen DM, Schmittdiel J, Hibbard J, Sobel D, Remmers C, Bellows J. Is patient activation associated with outcomes of care for adults with chronic conditions? Journal of Ambulatory Care Management. 2007; 30: 21-9.

14. Deen D, Lu W, Rothstein D, Santana L, Gold M. Asking questions: The effect of a brief intervention in community health centers on patient activation. Patient Education and Counseling. 2011; 84: 257-260.

15. Wong ST, Peterson S, Black C. Patient Activation in Primary Healthcare A Comparison Between Healthier Individuals and Those With a Chronic Illness. Medical Care. 2011; 49, 469-79.

16. Becker ER, Roblin DW. Translating Primary Care Practice Climate into Patient Activation The Role of Patient Trust in Physician. Medical Care. 2008; 46: 795-805.

17. Zill JM, Dwinger S, Kriston L, Rohenkohl A, Harter M, Dirmaier J. Psychometric evaluation of the German version of the patient activation measure (PAM 13). BMC Public Health. 2013; 13: 1-9.

18. Franz K, Hibbard J, Herrman W, Freund T, Szecseny J, et al. Validation of the German version of the patient activation measure 13 (PAM13-D) in an International Multicentre Study of Primary Care Patients. Plos One. 2013; 8: 1-6.
19. Maindal HT, Sokolowski I, Vedsted P. Translation, adaptation and validation of the American short form patient activation measure (PAM13) in a Danish version. BMC Public Health. 2009; 9: 1-9.

20. Ahn YH, Yi CH, Ham OK, Kim BJ. Psychometric properties of the Korean version of the "patient activation measure 13" (PAM13-K) in patients with osteoarthritis. Evaluation \& the Health Professions. 2014: 1-10.

21. Magnezi R, Glasser S. Psychometric properties of the Hebrew translation of the patient activation measure (PAM-13). Plos One. 2014; 9: 1-6.

22. Rademakers J, Nijman J, Hoek L, Heijmans M, Rijken M. Measuring patient activation in the Netherlands: translation and validation of the American short form Patient Activation Measure (PAM13). BMC Public Health. 2012; 12: 1-7.

23. Polit DF, Beck CT. The Content Validity Index: Are you sure you know what's being reported? critique and recommendations. Research in Nursing and Health . 2006; 29: 489-497.

24. Sencan H. Reliability and validity in social and behavioral measures. $1^{\text {st }}$ edition. Seckin Publishing. Ankara. 2005.

25. Gozum S, Aksayan S. Intercultural scale adaptation guide I: Scale adaptation steps andlanguage adaptation. Journal of Research and Development in Nursing. 2003; 4: 9-14. 26. Erkorkmaz U, Etikan I, Demir O, Ozdamar K, Sanioglu SY. Confirmatory FactorAnalysis and Compliance Indexes. Turkish Clinics J. Med. Sci. 2013; 33: 210-23.

27. Simsek OF. Introduction to Structural Equation Modeling. Istanbul Ekinoks Publications. 2007.

28. Buyukozturk S. Factor analysis: Basic Concepts And Use In Scale Development. Educational Management In Theory And Practice. 2002; 32: 470-480.

29. Kaynak ZN. Structural Equation Models. Istanbul Ticaret University. F.B.E. Department of Statistics Master Thesis. 2012.

30. Y1lmaz V. Lisrel ile Structural Equation Models: Application to Consumer Complaints. Journal of Social Sciences. 2004; 77-90.

31. Tavsancil E. Measuring Attitudes And Data Analysis With SPSS. 4. edition. Nobel Publishing Distribution. Ankara. 2006.

32. Baydur H. Eser E. Application: Psychometric analysis of the quality of life scales. Healtby Accumulation. 2006; 1. 